\title{
Caracterización morfoanatómica comparativa entre Aloe vera (L.) Burm. F., Aloe arborescens Mill., Aloe saponaria Haw. y Aloe ciliaris Haw. (Aloeaceae)
}

\author{
Stella Maris Carpano, María Teresa Castro, Etile Dolores Spegazzini* \\ Cátedra de Farmacobotánica, Facultad de Ciencias Exactas, UNLP, Calle 47 Y 115 (1900) La Plata, Buenos Aires, \\ Argentina
}

\begin{abstract}
RESUMO: Aloe vera (L.) Burm. F. (= Aloe barbadensis Miller) conhecida como "a planta da imortalidade" no antigo Egito é utilizada em fitoterapia como humectante, antibacteriana, antifúngica, antiviral e antioxidante. Com a finalidade de contribuir para identificação da droga vegetal, foram realizados estudos morfoanatômicos da folha. A utilização de plantas com características terapêuticas reconhecidas determina que, por analogia, popularmente sejam utilizadas com a mesma finalidade outras espécies do mesmo gênero. Isto é o que ocorre com três espécies de Aloe spp., que se cultivam ou crescem acidentalmente na Argentina: A. arborescens Mill., $A$. saponaria Haw. e $A$. ciliaris Haw. (Aloaceae). Estabeleceram-se os caracteres morfoanatômicos de diagnóstico por microscopia óptica e microscopia eletrônica de varredura (apresentam-se desenhos e fotomicrografias dos mesmos). Obtiveram-se valores numéricos dos elementos histológicos de diagnóstico: magnitudes lineares e proporcionais. Realizaram-se reações histoquímicas de identificação dos princípios ativos para sua localização "in situ”.
\end{abstract}

Unitermos: Aloaceae, Aloe vera, Aloe arborescens, Aloe saponaria, Aloe ciliaris.

\begin{abstract}
Comparative morphoanatomical characterization between Aloe vera (L.) Burm. F., Aloe arborescens Mill., Aloe saponaria Haw. and Aloe ciliaris Haw. (Aloaceae)". Aloe vera (L.) Burm. F. (= Aloe barbadensis Miller) known as "the plant of immortality" in ancient Egypt is used in phytotherapy as moisturizer, antibacterial, antifungal, antiviral and antioxidant. In Argentina it grows in the form adventitious or cultivated, Aloe arborescens Mill., Aloe saponaria Haw. and Aloe ciliaris Haw. (Aloaceae). In order to contribute to the identification of the drug plant the morphoanatomical characterization of the leaf was carried out. These species were studied with optical microscopy and scanning electron microscopy and the histochemical characteristics were studied in order to identify the active compounds. Morphoanatomical characteristics of these species were determined through lineal and proportional (stomatal index) parameters.
\end{abstract}

keywords: Aloaceae, Aloe vera, Aloe arborescens, Aloe saponaria, Aloe ciliaris.

\section{INTRODUCCIÓN}

Aloe vera fue conocida como "la planta de la inmortalidad" en el antiguo Egipto, también denominado la "planta bíblica" por la cantidad de veces que se menciona en el Antiguo como en el Nuevo testamento. Se relata que Nicodemo utilizó una mezcla de Aloe vera y mirra para embalsamar a Jesús. En la época de los romanos se utilizaban las hojas, tanto el gel incoloro como el mesófilo (Morton, 1961; Crosswhit, 1984). En nuestro país el uso popular reemplaza otras especies del género Aloe con iguales fines terapéuticos y cosméticos. A partir de ésto es imprescindible realizar la diferenciación de las especies en circulación a través del estudio morfoanatómico de cada una de ellas comparativo con A. vera para determinar el status taxonómico de las especies empleadas. Las plantas pertenecientes al género Aloe L. (1753) están incluídas actualmente en la familia Aloaceae (Van Wyk \& Smith, 1996). Son un grupo de plantas monocotiledóneas, perennes, con hojas suculentas, inflorescencias en panículas o racimos, con flores liliformes. Es una familia de amplia difusión, especialmente abundante en regiones tropicales y subtropicales, con enorme importancia económica y medicinal (Carter, 1994; Agra et al., 2007 y 2008; Oliveira et al., 2007; Silveira et al., 2008).

El origen del género Aloe ha sido discutido por varios investigadores (Cowling, 1982) sugiere que este grupo de plantas se originó en El Cabo oriental del sur de África (Holland, 1978) agrega que el antecesor de estas plantas tuvo su origen en las tierras altas de esa región africana, tiempo antes de la invasión del mar al canal de Mozambique, a mediados del periodo Cretáceo. Smith \& Steyn (2004) argumenta que el género Aloe se desarrolló plenamente a principios del Jurásico y también suministra evidencia de que el antecesor de este género fue una planta probablemente de unos $150 \mathrm{~mm}$ de altura. De aquí deriva que algunos autores consideren a las plantas de menor altura como las ancestrales de sus congéneres más altos. 
Desde el punto de vista citogenético, varios investigadores han estudiado los cariotipos de la familia Aloaceae (Valdés, 1997; Stack \& Anderson, 2001; Belmont, 2002; Pavlova \& Zakian, 2003) reiterando que este grupo de plantas es un ejemplo de gran estabilidad cromosómica, debido a la observación de un cariotipo bimodal constante, $2 \mathrm{n}=14$.

\section{MATERIAL Y MÉTODOS}

Se obtuvieron muestras de las hojas de un mismo ejemplar. Se conservan ejemplares de las especies en el Herbario de Botánica y Farmacognosia Carlos Spegazzini (LPE) de la Facultad de Ciencias Exactas de la Universidad Nacional de La Plata (UNLP). A. arborescens: Leg. Stella M. Carpano Argentina, Bs. As. La Plata, $\mathrm{N}^{\circ}$ 928, 948,951, (LPE); A. ciliaris: Leg. M. T. Castro, Argentina, Bs. As., La Plata, No 944,(LPE); A. saponaria: Leg. Etile Spegazzini, Argentina, Bs. As. Gonnet, No 929, 949,950 (LPE).

Los transcortes de hoja se efectuaron con un micrótomo de Ranvier a partir de material fresco. Se realizaron pruebas histoquímicas con azul de metileno para evidenciar mucílagos y amoníaco al $50 \%$ para poner de manifiesto los componentes químicos como aloína y barbaloína.

Las observaciones se realizaron con Microscopio óptico (MO) Olympus $\mathrm{CH}$ y las ilustraciones se hicieron mediante un tubo de dibujo Iroscope.

En lo referente a las técnicas empleadas para la observación con el Microscopio electrónico de barrido (MEB), trozos frescos de hojas se lavaron con agua destilada - detergente y se fijaron en etanol $96^{\circ}$, agua destilada, formol y ácido acético glacial (F.AA.) durante 48 horas. Finalmente bajo el microscopio estereoscópico se seccionó una pequeña pieza del material, se secó con papel de filtro y se montó sobre una platina cubierta con cinta adhesiva bifaz terminando el secado con la luz puntiforme del microscopio estereoscópico.

Las observaciones y fotomicrografías se efectuaron con un Jeol JSM-T 100 del Servicio de MEB del Museo La Plata, UNLP, Argentina.

\section{Descripción botánica - caracteres endomorfológicos}

\section{Aloe vera $\mathrm{L}$}

Planta acaulescente o de tallo corto. Hojas en roseta, extendidas o ascendentes, lanceoladas-atenuadas hacia el ápice, hasta $40-50 \mathrm{~cm}$ de de longitud y de 6 - $8 \mathrm{~cm}$ de ancho en la base, verdes, de márgenes con dientes de 2 - $3 \mathrm{~mm}$ de longitud y $1-1,5 \mathrm{~cm}$ de distancia .Inflorescencia racimosa simple o ramificada. Perianto de 2 - $3 \mathrm{~cm}$ de longitud, amarillo (Reynolds, 1950) (Figura $1)$.

\section{Aloe saponaria (Ait.) Haw}

Planta acaulescente o de tallo corto. Hojas en roseta, extendidas o ligeramente recurvadas, hasta $35 \mathrm{~cm}$ de longitud y de $8-12 \mathrm{~cm}$ de ancho en la base, de márgenes con dientes de $3-5 \mathrm{~mm}$ de longitud y 8 - $10 \mathrm{~mm}$ de distancia. La cara adaxial verde pálido a verde oscuro, con numerosas manchas oblongas claras ordenadas en hileras transversas, onduladas o partidas, cara abaxial usualmente mas pálida que la adaxial, sin manchas. Inflorescencias en panículas dicotómicamante ramificada. Periantos de 3 - $4 \mathrm{~mm}$ de longitud, anaranjado pálido. (Reynolds, 1950) (Figuras 2, 3).

\section{Aloe ciliaris Haw}

Planta decumbente con el tallo sarmentoso, largo y muy flexible. Hojas linear-lanceoladas, largamente acuminadas, extendidas a recurvadas, flexibles de 10 - 15 $\mathrm{cm}$ de longitud, 15 - $25 \mathrm{~mm}$ de ancho, abrazadoras con cilias en la aurícula foliar de $2-4 \mathrm{~mm}$ de longitud, verde oscuro a verde azulado de márgenes con dientes de $1 \mathrm{~mm}$ de longitud, $3 \mathrm{~mm}$ de distancia en la base disminuyendo gradualmente hacia el ápice. Inflorescencia racimosa simple. Perianto de 28 - $35 \mathrm{~mm}$ de longitud, escarlataamarillentas, verdosas en la parte superior (Reynolds, 1950) (Figura 2).

\section{Aloe arborescens Mill}

Planta con tallo erguido, bien desarrollado. Hojas en roseta, erectamente extendidas a extendidas deflexas, lanceoladas-acuminadas de $50-60 \mathrm{~cm}$ de longitud, 5 - 7 $\mathrm{cm}$ de ancho en la base, verde oscuro a verde azulado de márgenes con dientes curvados hacia delante de 3 - 5 $\mathrm{mm}$ de longitud, 5 - $20 \mathrm{~mm}$ de distancia. Inflorescencia racimosa usualmente simple. Perianto de $3,5 \mathrm{~cm}$ de longitud, escarlata. (Reynolds, 1950) (Figura 2).

\section{RESULTADOS Y DISCUSIÓN}

\section{Caracteres endomorfológicos}

\section{Aloe vera $\mathrm{L}$}

Microscopía óptica (Figura 4): Los transcortes de hoja muestran una epidermis, un parénquima homogéneo y una región central de parénquima incoloro entre ambos haces vasculares. Epidermis de células poligonales, isodiamétricas en vista superficial, revestidas por una cutícula ornamentada y gruesa con ceras. Estomas hundidos en ambas caras. Parénquima homogéneo con rafidios de oxalato de calcio. Haz vascular colateral, células secretoras formando casquete sobre el polo floemático rodeados por una vaina parenquimática.

Microscopía electrónica de barrido (Figura 5): Ornamentación de la cutícula con verrugas y tubéculos, libres y fusionados, y gránulos. 


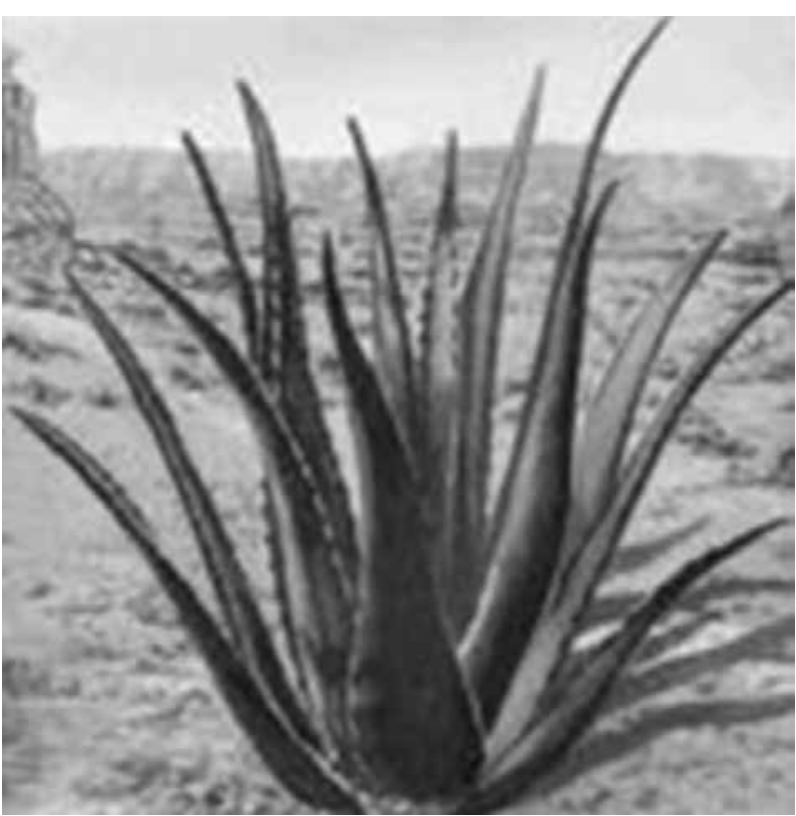

Figura 1. Aloe vera.

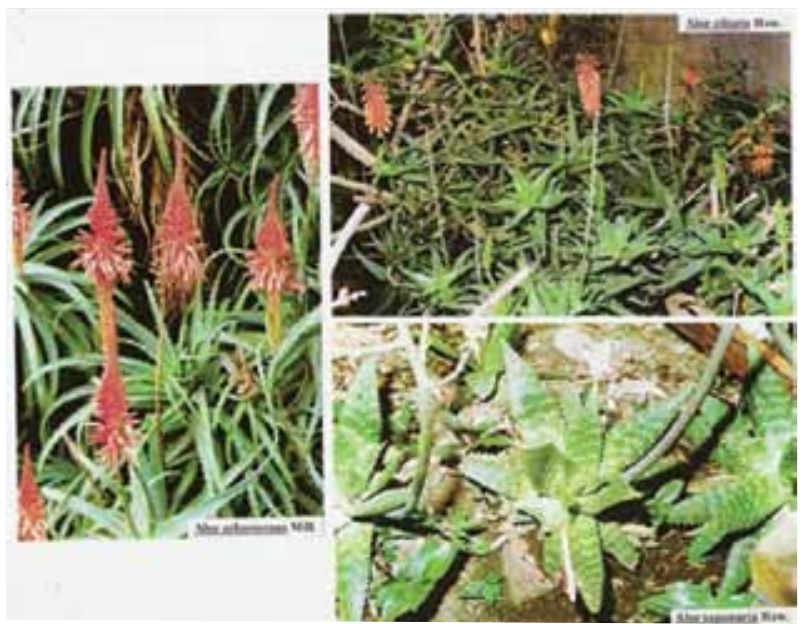

Figura 2. Especies de Aloe.

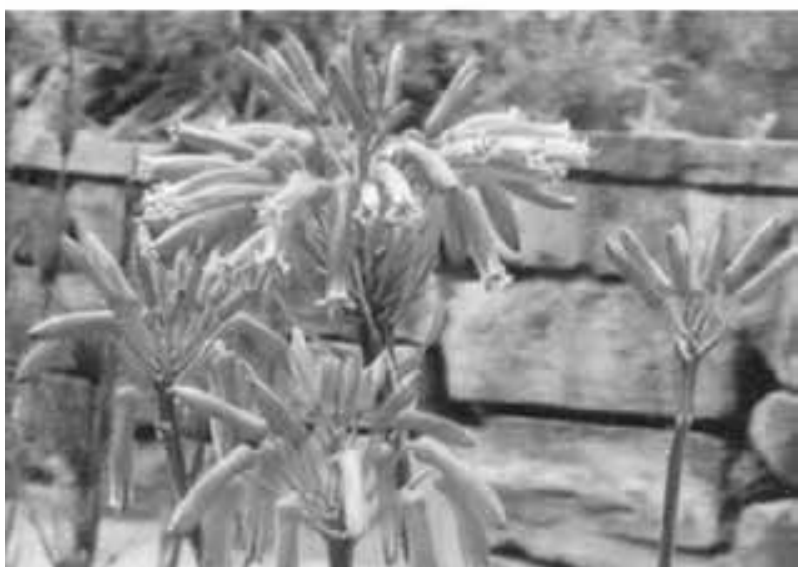

Figura 3. Inflorescencia de Aloe saponaria.

\section{Aloe saponaria (Ait.) Haw}

Microscopia óptica (Figura 4): Los transcortes de hojas muestran una epidermis, un parénquima homogéneo, una región central de parénquima incoloro y entre ambos haces vasculares. Epidermis de células poligonales, isodiamétricas en vista superficial revestidas por una cutícula ornamentada y gruesa con cera. Estomas hundidos en ambas caras. Parénquima homogéneo con rafidios de oxalato de calcio. Haz vascular colateral, células secretoras formando un casquete sobre el polo floemático rodeado por una vaina parenquimática.

Microscopía electrónica de barrido (Figura 6): Ornamentación de la cutícula con gránulos densamente distribuídos y generalmente fusionados. Escamas de cera. Límites de las células no ornamentados y cuando se elimina parcialmente la cutícula muestran una estría. Paredes externas de las células epidérmicas planas. Márgenes de las células subsidiarias protusivos con un anillo externo no rectangular, de ejes longitudinales convexos por debajo se encuentra la cavidad subestomática.

\section{Aloe ciliaris Haw}

Microscopía óptica (Figura 4): Los transcortes de hoja muestran una epidermis, un parénquima homogéneo, una región central de parénquima incoloro y entre ambos haces vasculares. Epidermis de células poligonales alargadas en vista superficial, revestida por una cutícula ornamentada, con cera. Estomas al mismo nivel que las células epidérmicas. Parénquima homogéneo con rafidios de oxalato de calcio Haz vascular colateral, rodeado por una vaina parenquimática.

Microscopía electrónica de barrido (Figura 7): Ornamentación de la cutícula con costillas que forman un diseño reticuloide. Contorno de las células epidérmicas bordeados por costillas, separadas por un leve surco. En células adyacentes cera en forma de partículas irregulares. Estomas con un anillo oval.

\section{Aloe arborescens Mill}

Microscopía óptica (Figura 4): Los transcortes de hoja muestran una epidermis, un parénquima homogéneo, una región central de parénquima incoloro y entre ambos haces vasculares. Epidermis de células poligonales, alargadas en vista superficial revestida por una cutícula ornamentada y gruesa, con cera. Estomas hundidos en amabas caras. Parénquima homogéneo con rafidios de oxalato de cálcio. Haz colateral sobre el polo floemático un casquete de células (4-6) incoloras, rodeados por una vaina parenquimática.

Microscopía electrónica de barrido (Figura 8): Ornamentación de la cutícula formada por gránulos, tubérculos, verrugas y costillas cortas, casi paralelas, los elementos generalmente se fusionan entre si. Cera en forma de escamas. Contornos de las células epidérmicas 


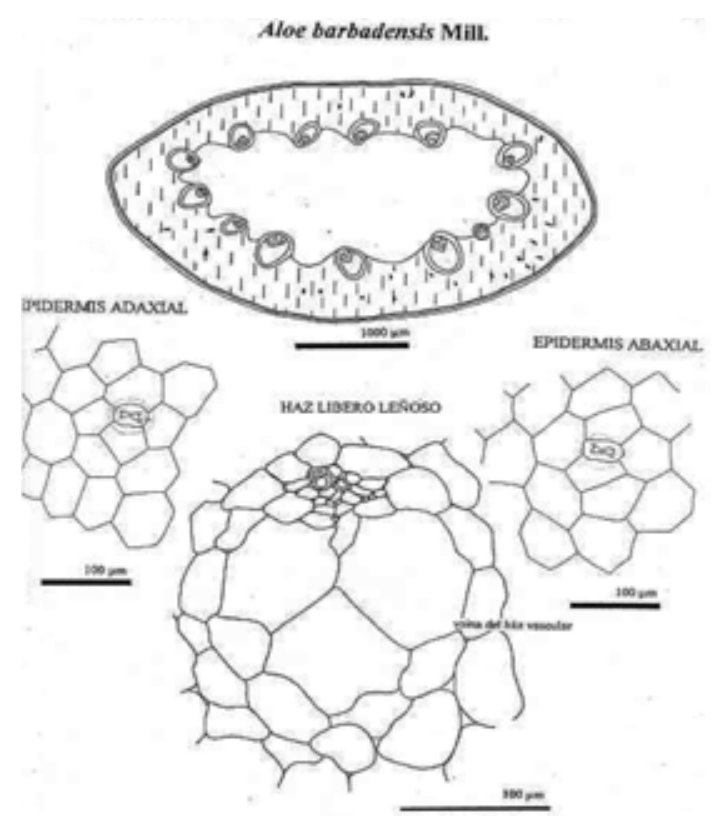

A

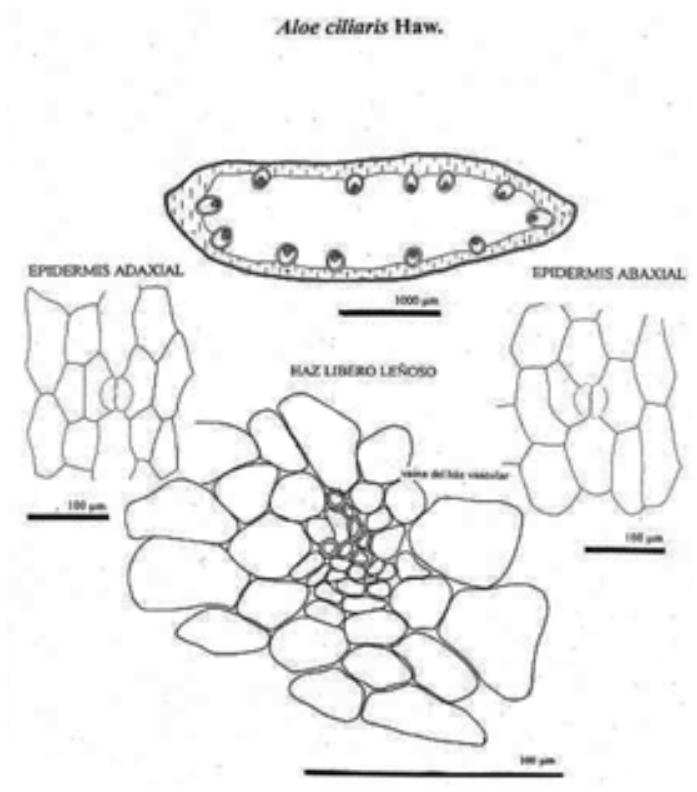

C

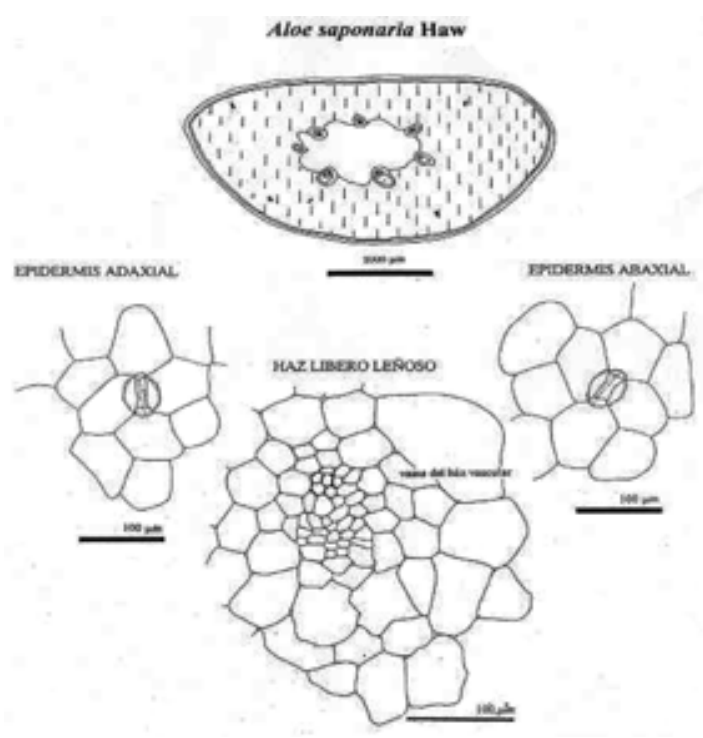

B

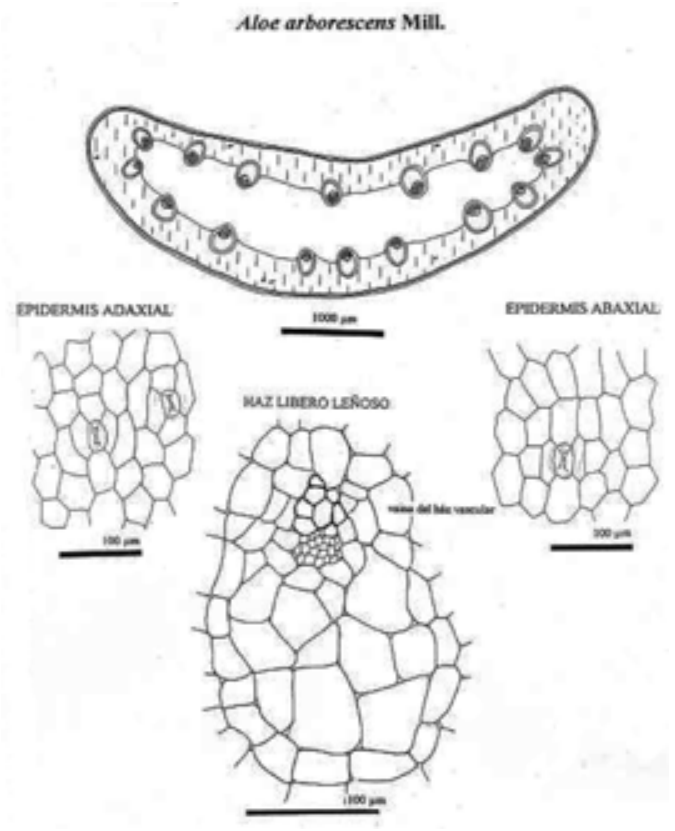

$\mathrm{D}$

Figura 4. Microscopía óptica de Aloe vera (=A. barbadensis), Aloe saponaria, Aloe ciliaris y Aloe arborescens. 
Aloe barbadensis Mill.

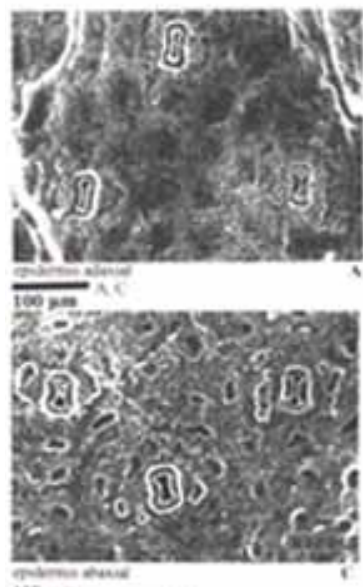

noe $=$
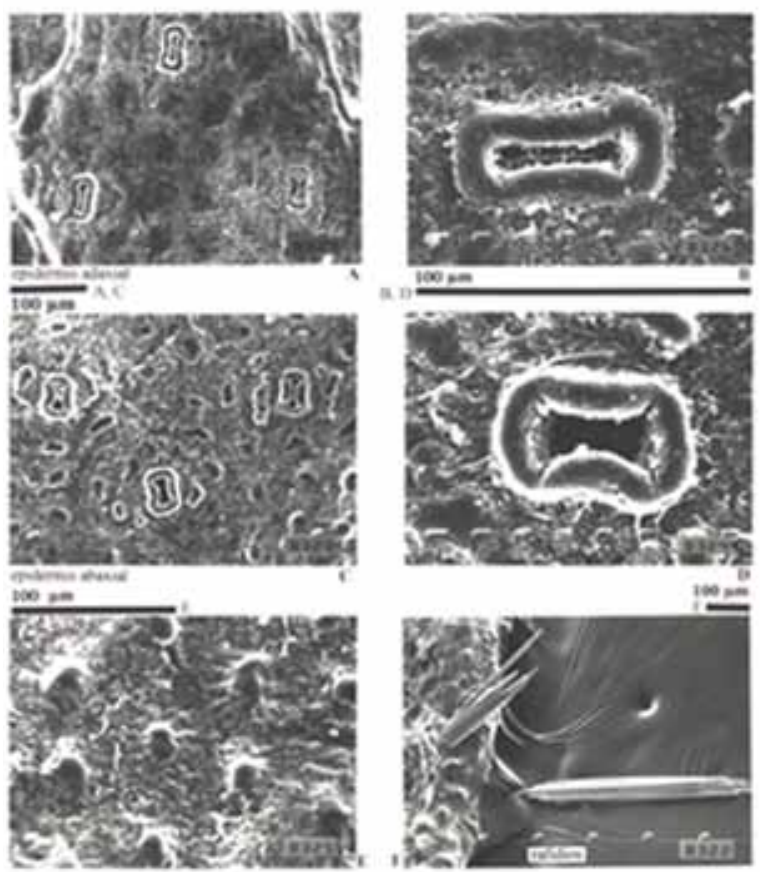

100

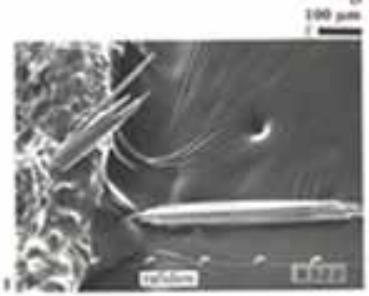

Figura 5. Microscopía electrónica de barrido de Aloe vera $=$ A. barbadensis.

Aloe saponaria Haw.
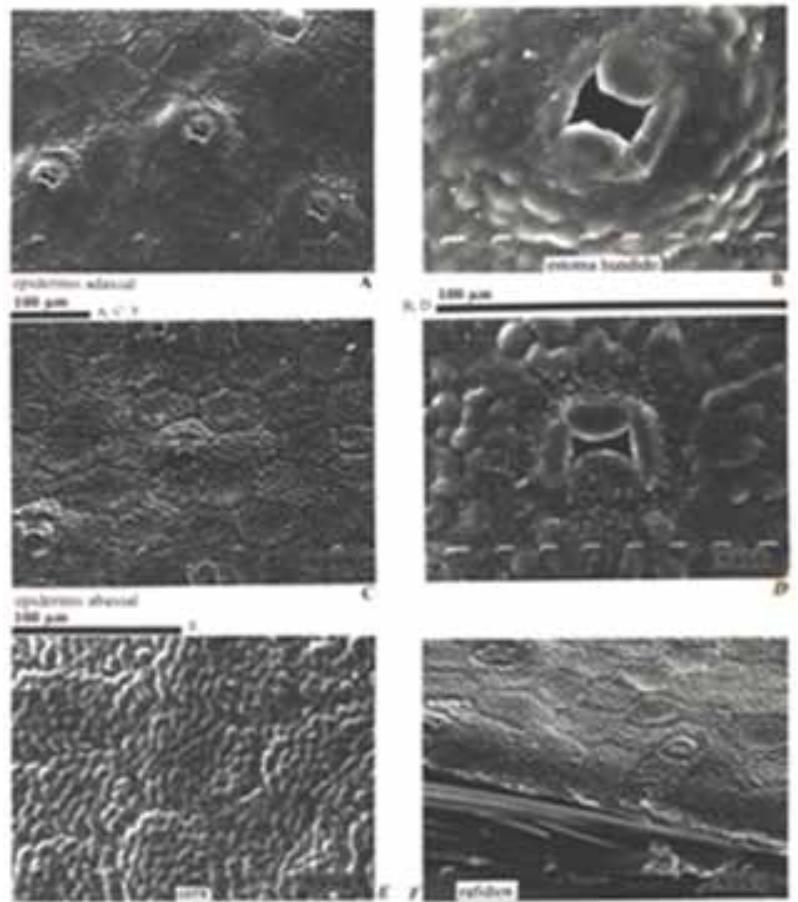

Figura 6. Microscopía electrónica de barrido de Aloe saponaria.
Aloe ciliaris Haw.
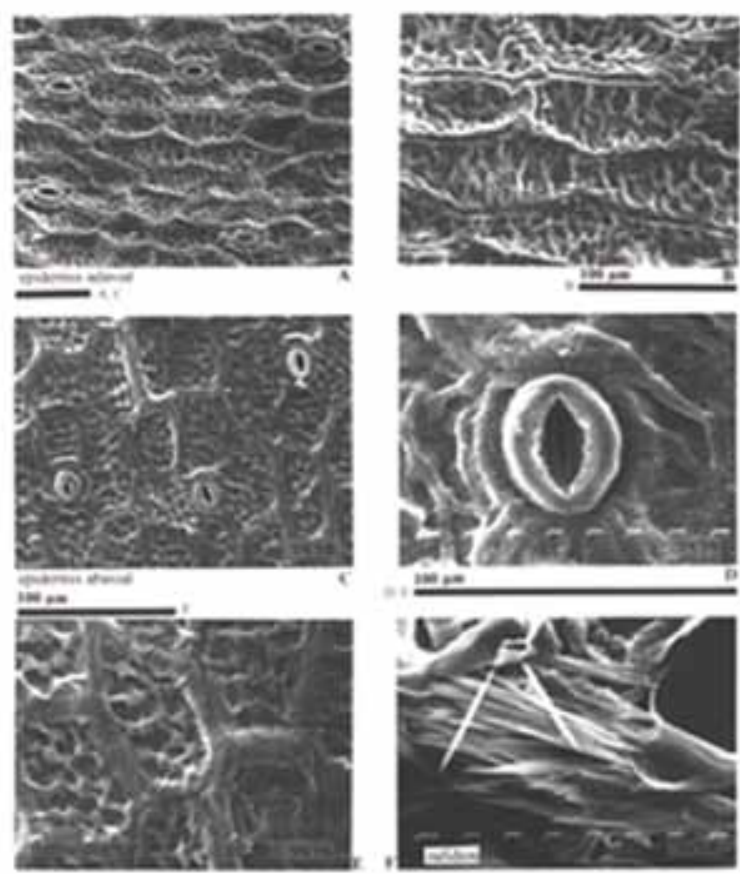

Figura 7. Microscopía electrónica de barrido de Aloe ciliaris.

Aloe arborescens Mill.
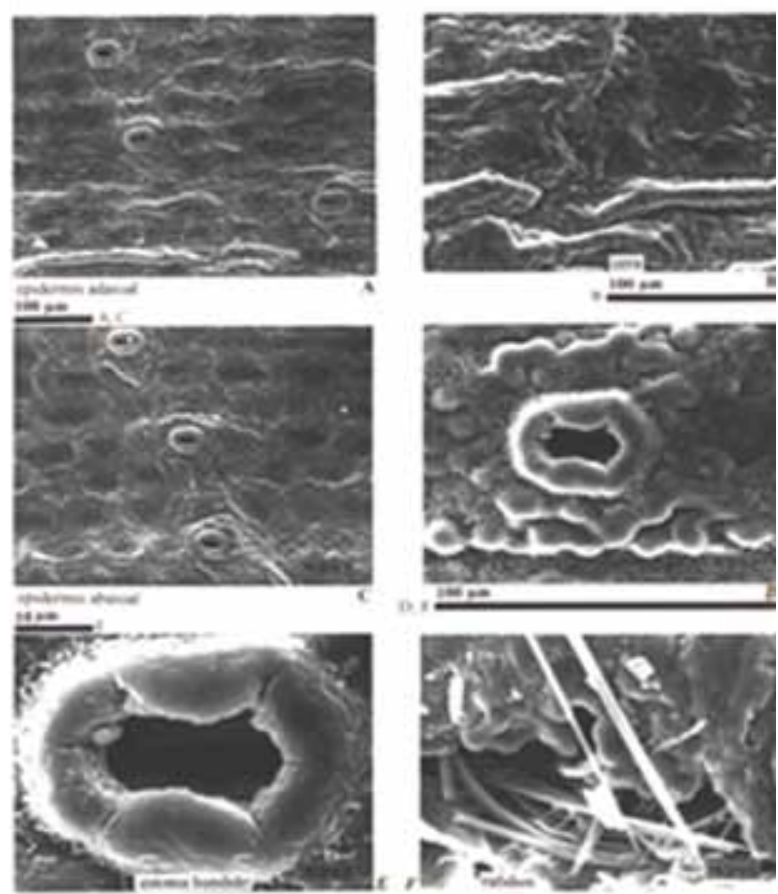

Figura 8. Microscopía electrónica de barrido de Aloe arborescens. 


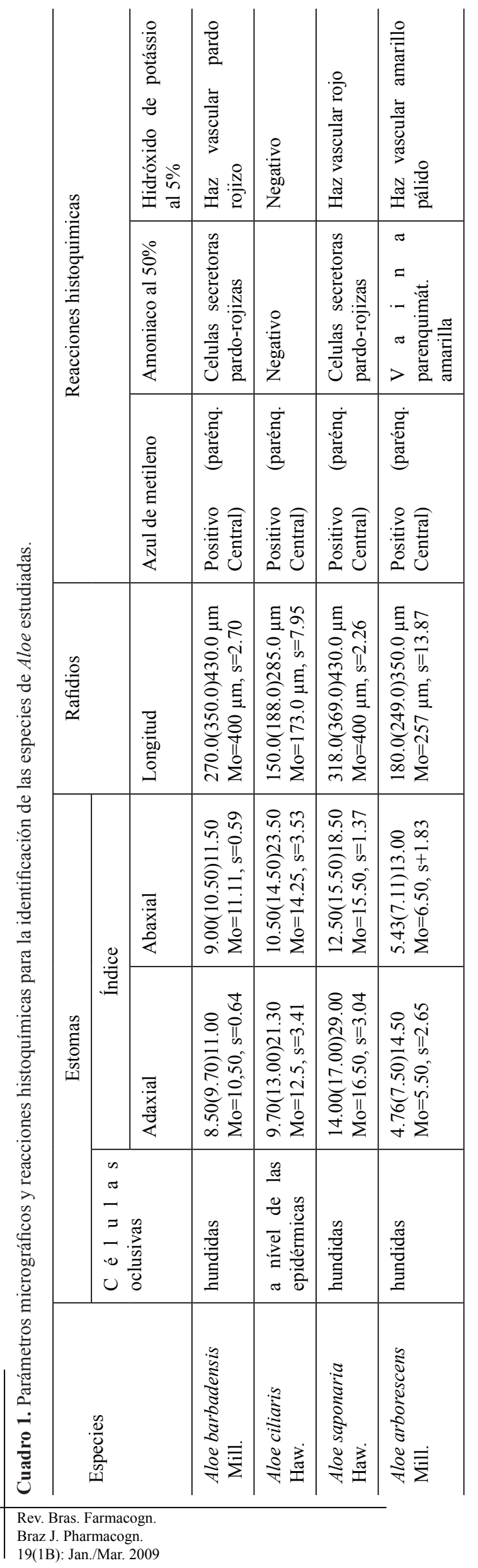


ornamentados y elevados en relación al área celular central. Márgenes de las células subsidiarias protusivos con una anillo oblongo, por debajo se halla la cavidad subestomáticas.

Parámetros micrográficos (Cuadro 1): Se indican los parámetros micrográficos y reacciones histoquímicas para la identificación de las especies de Aloe estudiadas.

\section{REFERENCIAS}

Agra MF, França PF, Barbosa-Filho JM 2007. Synopsis of the plants known as medicinal and poisonous in Northeast of Brazil. Rev Bras Farmacogn 17: 114-140.

Agra MF, Silva KN, Basílio IJLD, França PF, Barbosa-Filho JM 2008. Survey of medicinal plants used in the region Northeast of Brazil. Rev Bras Farmacogn 18: 472508 .

Belmont A 2002. Mitotic chromosome scaffold structure: new approaches to an old controversy. Proc Natl Acad Sci 99: 15855-15857.

Carter S 1994. Flora of tropical East Africa, Aloaceae. Royal Botanic Garden, Kew, U.K. 61 p.

Cowling RM 1982. Patterns of plant endemism in the south east Cape. The Naturalist 27: 17-36.

Crosswhit CD 1984. Aloe vera, plant symbolism and the threshing floor. Desert Plants 6: 43-50.

Holland PG 1978. An evolutionary biogeography of the genus Aloe. J Biogeogr 5: 213-226.

Morton JF 1961. Folk uses and commercial exploitation of Aloe leaf pulp. Econ Bot 15: 311-319.

Oliveira FQ, Gobira B, Guimarães C, Batista J, Barreto M, Souza M 2007. Espécies vegetais indicadas na odontologia. Rev Bras Farmacogn 17: 466-476.

Pavlova SV, Zakian SM 2003. Structural proteins of the SMC (Structural Maintenance of Chromosomes) family and their role in chromatin reorganization. Russ J Genet 39: 1097-1111.

Reynolds GW 1950. The aloes of South Africa. 520 pp.

Schmidt JM, Greenspoon JS 1991. Aloe vera dermal wound gel is associated with a delay in wound healing. Obstet Gynecol 78: 115-117.

Silveira PF, Bandeira MAM, Arrais PSD 2008. Farmacovigilância e reações adversas às plantas medicinais e fitoterápicos: uma realidade. Rev Bras Farmacogn 18: 618-626.

Smith GF, Steyn EMA 2004. Taxonomy of Aloaceae. In: Aloes, the genus Aloe. Reynolds, T. (Ed.). CRC Press. Boca Ratón, USA. pp. 15-36.

Stack SM, Anderson LK 2001. A model for chromosome structure during the mitotic and meiotic cell cycles. Chromosome Res 9: 175-198.

Valdés B 1997. Caracteres taxonómicos; citología y citogenética. (Eds. Izco J., Barreo E., Bruguéz M., Costa M., Devesa J., Fernández F., Gallardo T. Llimona X., Salvo E., Talavera S., Valdés B.) McGraw-Hill, Madrid (España), pp. 133-154.

Van-Wyk BE, Smith G 1996. Guide to aloes of South Africa. Briza Edic. Pretoria, South Africa. pp. 302. 